Irina Kostiv ${ }^{1}$, Olga Marshalok ${ }^{1}$, Galyna Marshalok ${ }^{2}$ and Igor Pyrig ${ }^{1}$

\title{
EFFECT OF THE REACTANTS MOLAR RATIO ON THE KINETICS OF THE REACTION TO OBTAIN 2-HYDROXYETHYL-1,3,4 TRIMETHYL-CYCLOHEX-3-EN CARBOXYLATE
}

\author{
${ }^{1}$ Lviv Polytechnic National University 12 , S. Bandery str.,79013 Lviv, Ukraine \\ $2 \mathrm{~J}$ an and J edrzej Sniadecki University of Technology and Life Sciences in Bydgoszcz \\ Ks. Kordecki Str. 20, 85-225 Bydgoszcz, Poland
}

Received: March 19, 2014 / Revised: A pril 10, 2014 / Accepted: August 25, 2014

(C) Kostiv I., Marshalok O., Marshalok G., Pyrig I., 2015

\begin{abstract}
Kinetic aspects of the reaction of 2-hydroxyethyl1,3,4-trimethylcyclohex-3-ene-1-carboxylate obtaining have been investigated. On the basis of the obtained results the kinetics of the process has been studied by the MichaelisMenten equation. The limiting stage of the reaction is established and its mechanism is suggested.
\end{abstract}

Keywords: 2,3-dimethylbuta-1,3-diene, 2-hydroxyethylmethacrylate, 2-hydroxyethyl-1,3,4-trimethylcyclohex-3ene-1-carboxylate, Michaelis-Menten equation.

\section{Introduction}

Michaelis-Menten kinetics is one of the most famous models describing the kinetics of reactions occurring through a stage of equilibrium. One of the most important parameters of the reactions kinetics occurring<smiles>C=C(C)C(=C)[CH+]C(=C)C(=O)OCCO</smiles>

by this mechanism is the dependence of the process on the concentration of the reactants. The first stage of this reaction is an equilibrium phase during which the intermediate complex is formed, the next step is irreversibly converted into the reaction product according to the theory of Michaelis-Menten [1].

In order to establish the mechanism of the DielsAlder reaction in the present work we studied the kinetics of the interaction of 2,3-dimethylbuta-1,3-diene with 2hydroxyethylmethacrylate.

\section{Experimental}

2-Hydroxyethyl-1,3,4-trimethylcyclohex-3-encarboxylate was received via the cyclization of 2,3-dimethylbuta-1,3-dien with 2-gydroxyethylmethacrylate in accordance with the Diels-Alder reaction.<smiles>CC1=C(C)CC(C)(C(=O)OCCO)CC1</smiles>

Effective rate constants and activation parameters of the cycloaddition reaction between 2,3-dimethylbuta-1,3-diene and 2-hydroxyethylmethacrylate

\begin{tabular}{|c|c|c|c|c|c|c|c|}
\hline \multirow{2}{*}{ Molar ratio HEMA : DMB } & \multicolumn{4}{|c|}{$k_{e f f} \cdot 10^{6}, 1 \mathrm{~mol}^{-1} \mathrm{~s}^{-1}$} & \multirow{2}{*}{$\begin{array}{c}E_{e f f}, \\
\mathrm{~kJ} \mathrm{~mol}^{-1}\end{array}$} & \multirow{2}{*}{$\begin{array}{c}\Delta H_{e f f}, \\
\mathrm{~kJ} \mathrm{~mol}^{-1}\end{array}$} & \multirow{2}{*}{$\begin{array}{c}\Delta S_{\text {eff }}, \\
\mathrm{J} \mathrm{mol}^{-1} \mathrm{~K}^{-1}\end{array}$} \\
\hline & $403 \mathrm{~K}$ & $413 \mathrm{~K}$ & $423 \mathrm{~K}$ & $433 \mathrm{~K}$ & & & \\
\hline $1: 1$ & 1.50 .1 & $2.3 \pm 0.1$ & $3.6 \pm 0.2$ & $6.1 \pm 0.3$ & 67.5 & 64.0 & -181 \\
\hline $1: 1.25$ & $1.7 \pm 0.1$ & $3.0 \pm 0.1$ & $4.7 \pm 0.2$ & $7.3 \pm 0.3$ & 70.0 & 66.5 & -173 \\
\hline $1: 1.4$ & $2.0 \pm 0.1$ & $3.7 \pm 0.2$ & $5.8 \pm 0.3$ & $8.9 \pm 0.4$ & 71.6 & 68.1 & -168 \\
\hline $1: 1.5$ & $2.2 \pm 0.1$ & $4.2 \pm 0.2$ & $6.9 \pm 0.3$ & $10.1 \pm 0.5$ & 73.7 & 70.2 & -162 \\
\hline $1: 1.6$ & $2.6 \pm 0.1$ & $4.8 \pm 0.2$ & $7.7 \pm 0.4$ & $12.5 \pm 0.5$ & 75.3 & 71.8 & -157 \\
\hline $1: 1.75$ & $3.1 \pm 0.2$ & $6.0 \pm 0.3$ & $9.8 \pm 0.5$ & $15.2 \pm 0.6$ & 76.4 & 72.9 & -152 \\
\hline
\end{tabular}


For synthesis 2-hydroxyethylmethacrylate of "chemically pure" type and previously synthesized by us 2,3-dimethylbuta-1,3-dien according to [2,3] were used.

Kinetic studies were performed in temperaturecontrolled sealed glass ampules according to the method described in [4], in the temperature range of 403-433 K. The ampules $\left(10 \mathrm{~cm}^{3}\right)$ were charged with 2hydroxyethylmethacrylate and 2,3-dimethylbuta-1,3-diene in the molar ratios $1: 1,1: 1.25,1: 1.4,1: 1.5,1: 1.6$, $1: 1.75$, hydroquinone was added; then the ampules were sealed and placed in a thermostat. At regular intervals, an ampule was removed from the thermostat, quickly cooled, opened, and the reaction mixture was analyzed by gasliquid chromatography on SELMI CHROM-1 apparatus. The quantitative analysis was performed with internal normalization. The accuracy of chromatographic analysis in multiple parallel determinations did not exceed $3 \%$ [5].

\section{Results and Discussion}

On the basis of previously carried out kinetic experiments it was established that cycloaddition reaction between 2,3-dimethylbuta-1,3-diene and 2-hydroxyethylmethacrylate is satisfactorily described by the kinetic equation of the irreversible reaction of the second order. The values of effective rate constants are listed in Table 1.

We found that the values of the effective secondorder constants increase with the increasing ratio of 2,3-dimethylbuta-1,3-diene : 2-hydroxyethylmethacrylate. The difference is more pronounced at higher temperatures. It was appropriate to examine in more details the mechanism of this reaction. Note that the mechanism of [4+2]cycloaddition reaction today is still controversial [6].

Two concerted mechanisms are suggested: a singlestep (sinchronous) and a two-step ones, in which the first step is the limiting one [7]. The Arrhenius equation satisfactorily described the dependence of the effective rate constants on temperature for different ratios (Fig. 1), which allowed us to calculate the formal activation energy and other activation parameters of the overall process (Table 1).

The correlation coefficient was satisfactory in all cases $\left(R^{2}>0.95\right)$. The analysis of the parameters made it possible to establish that upon increase in 2,3dimethylbuta-1,3-diene excess accompanying the increase in $k_{\text {eff }}$ values a systematic increase was observed in the effective energy $\left(\Delta E_{\text {eff }}\right)$ and the effective activation enthalpy $\left(\Delta H_{\text {eff }}\right)$. Simultaneously, the value of the effective activation entropy $\left(-\Delta S_{\text {eff }}\right)$ also increases.

For all ratios of reagents an isokinetic relationship was observed with a high degree of correlation $\left(R^{2}=0.99\right)$ between the effective entropy and enthalpy of the reaction, which allowed to calculate of the isokinetic temperature $T_{\text {iso }}=315 \mathrm{~K}$ (Fig. 2) that was far from the investigated temperature range.

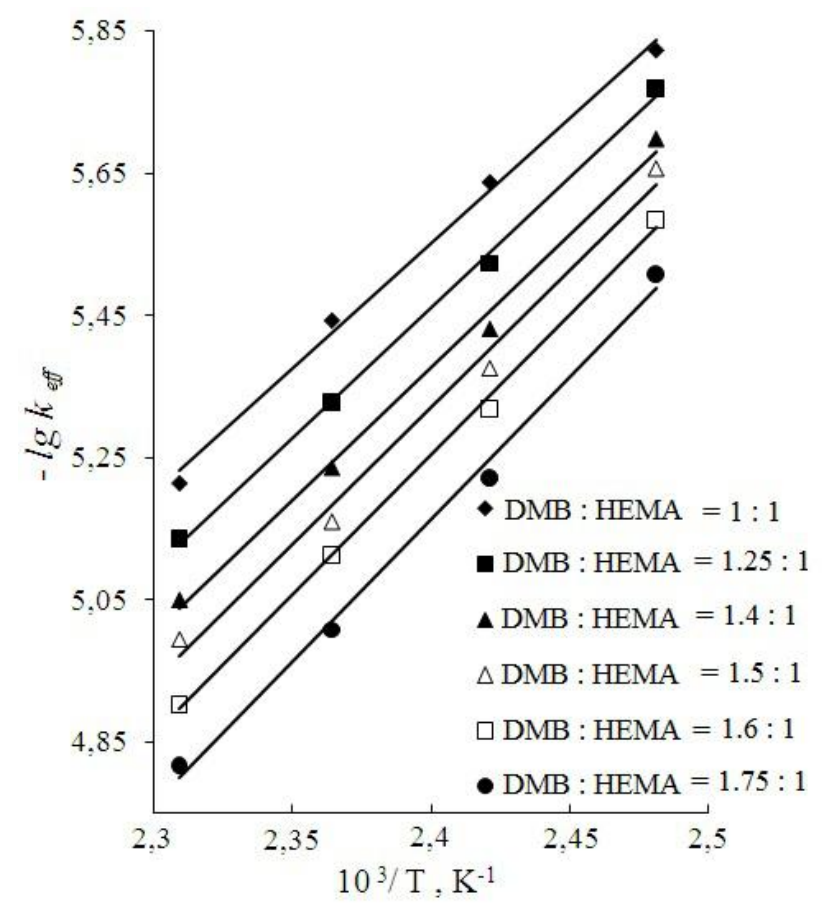

Fig. 1. Dependence of the effective rate constant of cycloaddition between 2,3-dimethylbuta-1,3-diene and 2-hydroxyethylmethacrylate on temperature for different ratios of reactants 2,3-dimethylbuta-1,3diene : 2-hydroxyethylmethacrylate

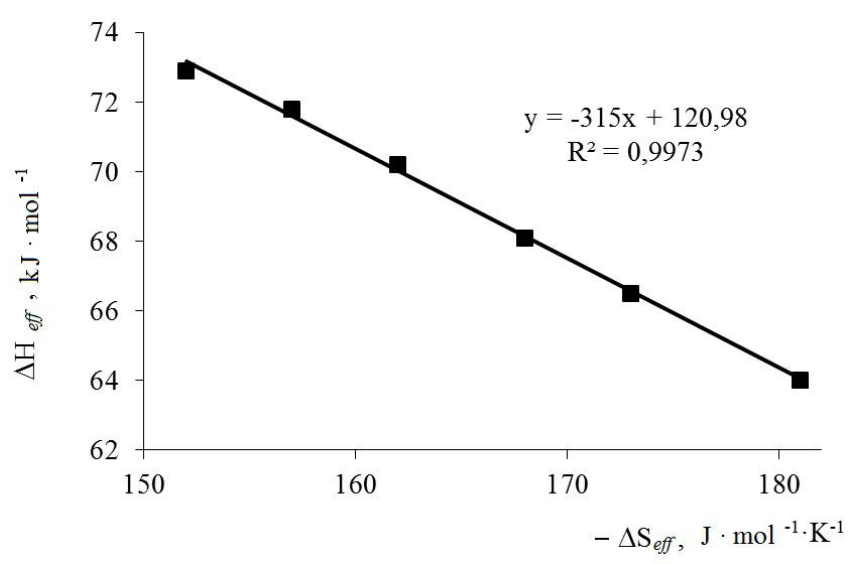

Fig. 2. Dependence of the effective activation entropy on the effective activation enthalpy of the cycloaddition between 2,3-dimethylbuta-1,3-diene and 2-hydroxyethylmethacrylate

The increase in $E_{\text {eff }}$ and $\Delta H_{\text {eff }}$ with an increasing excess of 2,3-dimethylbuta-1,3-diene and a simultaneous increase in $\Delta S_{\text {eff }}$ indicate the increasing steric hindrances in the reaction course. This finding also suggests that the reaction mechanism is unique in the studied range of the 
reagents ratio. Such systematic change in the rate constants with an increase in excess of one of the reactants is typical of the reactions that include the formation of the charge transfer complex (CTC by the reagents) $[8,9]$. A similar reaction course has also been proved for several cases, including the alcoholysis of alcohols [10, 11], where the formation of charge-transfer complexes was confirmed by the methods of physicochemical and spectral analyses.

For these reactions the effective second-order rate constant does not remain constant changing the reagent ratio, and the kinetics of the process is described by the Michaelis-Menten equation:

$$
\begin{gathered}
\mathrm{A}+\mathrm{B} \stackrel{\mathrm{K}_{\mathrm{eq}}}{\longrightarrow}[\mathrm{A}: \mathrm{B}] \stackrel{\mathrm{k}_{\mathrm{conv}}}{\longrightarrow} \text { Product } \\
\frac{1}{k_{\mathrm{eff}}}=\frac{1}{k_{\mathrm{conv}}}-\frac{\mathrm{K}_{e q} \mathrm{C}_{\mathrm{A}}}{k_{\mathrm{conv}}}
\end{gathered}
$$

where $k_{\text {eff }}$ is experimentally determined effective second order rate constant for each reagent ratio, $1 \mathrm{~mol}^{-1} \mathrm{~s}^{-1}$; $K_{e q}$ is the equilibrium constant for the intermediate complex formation, $1 \mathrm{~mol}^{-1} ; k_{\text {conv }}$ is the rate constant of the intermediate complex conversion into the reaction product, $\mathrm{s}^{-1} ; C_{\mathrm{A}}$ is the molar concentration of the substance taken in excess.

In our case, the change in the effective rate constants of 2,3-dimethylbuta-1,3-diene cycloaddition to 2-hydroxyethylmethacrylate as a dependence on the ratio of reactants is also satisfactorily described by the Michaelis-Menten equation (2) (Fig. 3). This fact suggests that the cycloaddition reaction between 2,3-dimethylbuta1,3-diene and 2-hydroxyethylmethacrylate proceeds through a stage of equilibrium with the formation of an intermediate complex followed by its conversion into the reaction product (Eq. (3)).<smiles>C=C(C)C(=C)C</smiles><smiles>Cc1ccc(C(=O)OCCO[CH+]C2CC2)cc1C</smiles>

From the dependences shown in Fig. 3 for four temperatures, we obtained the following linear equations:

$$
\begin{aligned}
& 403 \mathrm{~K}: 1 / k_{\text {eff }}=-340146 C_{A}+838510,\left(R^{2}=0.998\right) \\
& 413 \mathrm{~K}: 1 / k_{\text {eff }}=-244294 C_{A}+520041,\left(R^{2}=0.991\right) \\
& 423 \mathrm{~K}: 1 / k_{\text {eff }}=-161490 C_{A}+338760,\left(R^{2}=0.994\right) \\
& 433 \mathrm{~K}: 1 / k_{\text {eff }}=-94241 C_{A}+209279,\left(R^{2}=0.992\right)
\end{aligned}
$$

The slope of the obtained straight lines gives the rate constants of the conversion of the intermediate complex in the reaction product $\left(k_{\text {conv }}\right)$. The values of the intercepts on the ordinate axis give the equilibrium constants of the complex formation (Table 2) according to the expression $K_{e q}=1 /\left(k_{\text {eff }} k_{\text {conv }}\right)$.

The dependence of the equilibrium constant $\left(K_{e q}\right)$ of the intermediate complex formation is described by the isobar (Fig. $4, R^{2}>0.98$ ). The dependence of the rate constants of conversion $\left(k_{\text {conv }}\right)$ on the temperature is described by the Arrhenius equation (Fig. $5, R^{2}>0.99$ ), which allows the calculation of the activation parameters of the intermediate complex conversion in the reaction product (Table 2).<smiles>CC1=C(C)CC(C)(C(=O)OCCO)C1</smiles>

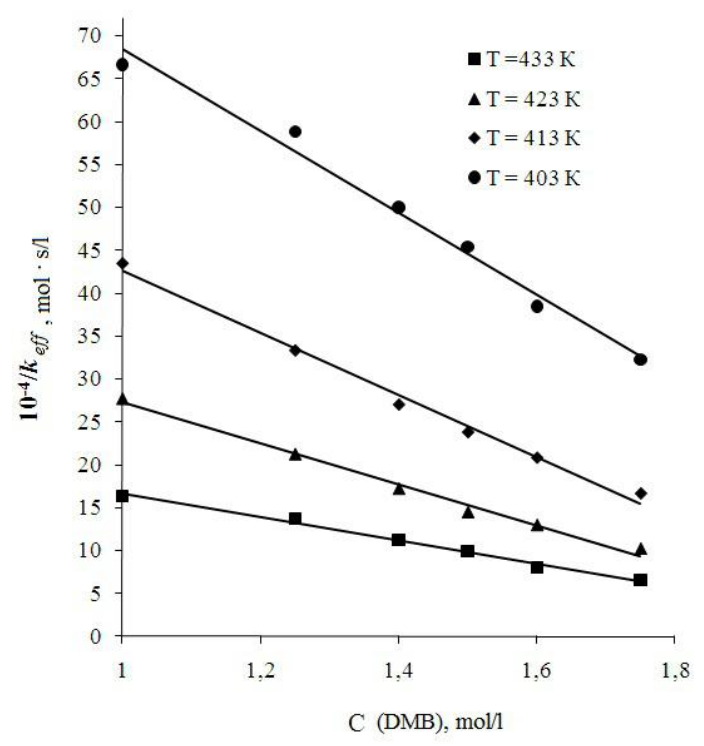

Fig. 3. Dependence of the effective rate constant of cycloaddition between 2,3-dimethylbuta-1,3-diene and

2-hydroxyethylmethacrylate on the $C_{0}$ of 2,3-dimethylbuta-1,3dien (DMB) in the temperature range of $403-433 \mathrm{~K}$ 


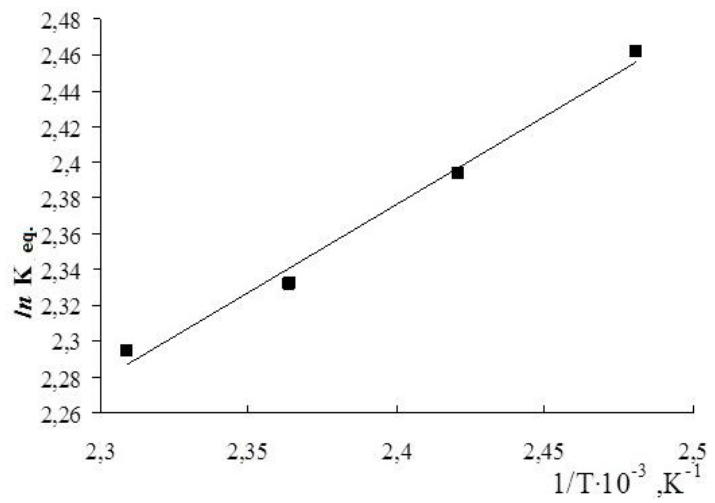

Fig. 4. Dependence of the equilibrium constant of the formation of intermediate complex on the temperature

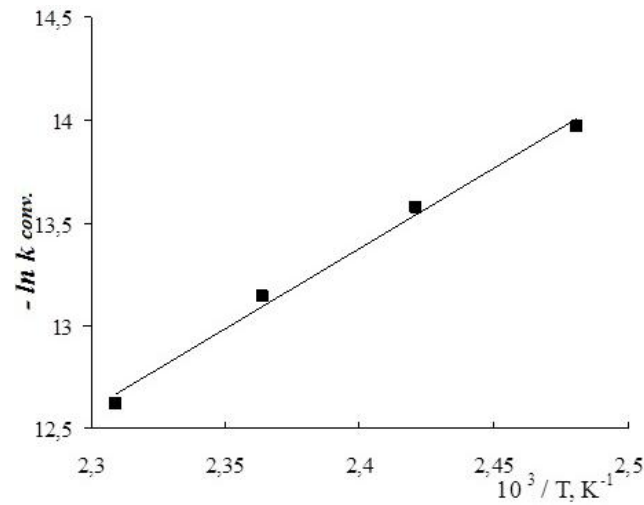

Fig. 5. Dependence of the rate constants of the intermediate complex conversion in the reaction product on the temperature

Table 2

Equilibrium constants $\left(k_{e q}\right)$ and thermodynamic parameters of formation of the intermediate complex, the rate constants $\left(\boldsymbol{k}_{\text {conv }}\right)$ and activation parameters of its transformation into a product of the reaction

\begin{tabular}{|c|c|c|c|c|c|c|c|}
\hline Constants & $403 \mathrm{~K}$ & $413 \mathrm{~K}$ & $423 \mathrm{~K}$ & $433 \mathrm{~K}$ & $\Delta H_{e q}, \mathrm{~kJ} \mathrm{~mol}^{-1}$ & $\Delta S_{e q}, \mathrm{~J} \mathrm{~mol}^{-1} \mathrm{~K}^{-1}$ & $\Delta G_{e q}, \mathrm{~kJ} \mathrm{~mol}^{-1}$ \\
\hline $\begin{array}{c}K_{e q} \cdot 10^{2} \\
1 \cdot \mathrm{mol}^{-1}\end{array}$ & 8.33 & 9.55 & 9.81 & 10.08 & 8.9 & -242 & 85 \\
\cline { 5 - 8 } & & & & $E_{\text {conv }}, \mathrm{kJ} \mathrm{mol}^{-1}$ & $\Delta H_{\text {conv }}^{\#}, \mathrm{~kJ} \mathrm{~mol}^{-1}$ & $\Delta S_{\text {conv }}^{\#}, \mathrm{~J} \mathrm{~mol}^{-1} \mathrm{~K}^{-1}$ \\
\hline$k_{\text {conv } .} \cdot 10^{6}, \mathrm{~s}^{-1}$ & 0.86 & 1.27 & 1.96 & 3.30 & 64.7 & 57.8 & -193 \\
\hline
\end{tabular}

The found positive $\Delta G_{e q}=85 \mathrm{~kJ} \cdot \mathrm{mol}^{-1}$ and negative $\Delta S_{e q}=-242 \mathrm{~J} \mathrm{~mol}^{-1} \mathrm{~K}^{-1}$ values indicate the energy advantage of the intermediate complex formation. At the same time a relatively fast decomposition of the intermediate complex suggests that its formation is the limiting stage of the process.

\section{Conclusions}

Thus, we established for the first time that the kinetics of the investigated process obeyed the MichaelisMenten equation, which was valid in the case of the reaction course through the stage of the associative equilibrium. It is an argument in favor of this reaction to proceed by the mechanism of concerted cycloaddition. It is known that the addition of a diene molecule to the dienophile double bond originates from a certain deficiency of the electron density on this double bond due to its interactions with other active groups, the stronger conjugation with them, the easier the diene addition is.

The results of the study of kinetic regularities in the process of 2-hydroxyethyl-1,3,4-trimethylcyclohexa-3-ene-1carboxylate synthesis and the study of this reaction mechanism showing its corresondence to the MichaelisMenten equation confirm the formation of an intermediate complex between the reagents, 2,3-dimethylbuta-1,3-diene and 2-hydroxyethylmethacrylate. The study of thermodynamic parameters of the intermediate complex formation suggests that the limiting stage is the slow formation of an intermediate complex, the activation parameters of the intermediate complex transformation in the product indicates that the conversion of the intermediate complex in the product occurs rapidly and spontaneously.

\section{References}

[1] Voet D. and Voet J.: Biochemistry $4^{\text {th }}$ edn., Wiley, NY 2011.

[2] Polyova I., Marshalok G., Fedevych M. et al.: UA Pat. 46772, MPK C 07 C 11/00. Publ. Jan. 11, 2010.

[3] Polyova I., Marshalok G., Fedevych M. et al.: UA Patent 52884, MPK C 07 C 11/00. Publ. Sept. 10, 2010.

[4] Polyova I., Polyuzhin I., Marshalok G. and Gladii A.: III Vseukr. Nauk. Konf. Stud. i Asp. "Khimichny Karazinski Chitaniya 2011", Kharkov 2011, 41.

[5] Shmid R. and Sapunov V.: Neformal'naya Kinetika. Mir, Moskwa 1985.

[6] Jasinski R., Kwiatnowska M. and Baranski A.: Wiadom. Chemiczne, 2007, 61, 485-514.

[7] Woodward R. and KatzT.: Tetrahedron, 1959, 5, 70-89.

[8] Ross S. and Kuntz J.: J. Am. Chem. Soc., 1954, 76, 3000-3012.

[9] Hammett L.: Physical Organic Chemistry. McGraw-Hill, New York 1970.

[10] Marshalok G., Oglashennyi Yu., Makitra R. and Yatchishin I.: Zh. Org. Khim., 2003, 39, 1221-1226.

[11] Makitra R., Tsikanchuk Ya. and Turkevich O.: Dokl. Akad. Nauk SSSR, 1976, 5, 435-437.

\section{ВПЛИВ МОЛЯРНОГО СПІВВІДНОШЕННЯ РЕАГЕНТІВ НА КІНЕТИЧНІ АСПЕКТИ РЕАКЩЇ ОДЕРЖАННЯ 2-ГІДРОКСИЕТИЛ-1,3,4- ТРИМЕТИЛЦИКЛОГЕКС-3-ЕНКАРБОКСИЛАТУ}

Анотація. Досліджено кінетичні аспекти реакції одержсання 2-гідроксиетил-1,3,4-триметилциклогекс-3енкарбоксилату. На основі отриманих результатів встановлено, щуо кінетика досліджуваного процесу підпорядковусться рівнянню Міхаеліса-Ментен. Встановлена лімітуюча стадія реакиії та запропонований ї̈ механізм.

Ключові слова: 2,3-диметилбута-1,3-дієн, 2-гідроксиетилметакрилат, 2-гідроксиетил-1,3,4-триметилциклогекс-3-енкарбоксилат, рівняння Міхаеліса-Ментен. 